\title{
El Poder del Arte en el Mundo Maya
}

Judith M. Maxwell

\section{Resumen}

La película Apocaliypto recreó mucho del arte de las ciudades clásicas y postclásicas de las Tierras Bajas mayas. El paisaje urbano, una mezcla de edificios parecidos a los de El Mirador, techos de peine al estilo de Tikal y los rasgos de la escultura del Puuc, centelleando con los colores primarios vívidos que adornaban a las ciudades vivientes mayas. Los murales de San Bartolo, con ciertos agregados sangrientos, merodeaban por la mente a la entrada del protagonista a la plaza central de la ciudad. La vestimenta de los nobles trajo a la mente la de figuras de estelas y de vasijas. La representación de una ciudad maya pre-invasión pudo haber sido el sueño de un mayista. No obstante, para la mayoría de nosotros esta película soñada se convirtió en una pesadilla. Este artículo explora el poder de la representación del arte maya en la actualidad.

Palabras Clave: Apocalypto, arte maya, poder de la representación visual.

\section{Abstract}

Apocalypto, the movie, recreated much of the art from the classic and post-classic cities of the maya lowlands. The urban landscape, a mixture of buildings similar to those of El Mirador, roof combs Tikal-style and features of Puuc sculpture glinting with the vivid primary colors that adorn the living maya cities. The San Bartolo murals, with some bloody additions prowling in the mind when the main character entered the city's central plaza. The nobles' clothing brought to mind those of the stelae figures and vessels. The presentation of a pre-invasion maya city could have been a mayist's dream. However, for most of us the dream movie became a nightmare. This article explores the power of representation of maya art in contemporary times.

Keywords: Apocalypto, maya art, power of visual representation.

Judith M. Maxwell (maxwell@tulane.edu), Universidad de Tulane (Tulane University). 


\section{INTRODUCCIÓN}

El 8 de diciembre de 2006, el arte maya irrumpió en los teatros de los Estados Unidos como el escenario para reiterar el argumento favorito de Mel Gibson, un buen hombre defendiendo a su familia y sus valores en contra de una sociedad enloquecida. Apocalypto, con la asesoría técnica del arqueólogo Richard Hansen, recreó mucho del arte de las ciudades clásicas y postclásicas de las Tierras Bajas mayas. El paisaje urbano, una mezcla de edificios parecidos a los de El Mirador, techos de peine al estilo de Tikal (dados a conocer anteriormente al mundo por medio de Star Wars como la base de resistencia de los rebeldes) y los rasgos de la escultura del Puuc, centelleando con los colores primarios vívidos que adornaban a las ciudades vivientes mayas. Los murales de San Bartolo, con ciertos agregados sangrientos, merodeaban por la mente a la entrada del protagonista a la plaza central de la ciudad. La vestimenta de los nobles trajo a la mente la de figuras de estelas y de vasijas. La representación de una ciudad maya pre-invasión pudo haber sido el sueño de un mayista. En realidad, Gibson se sobrepasó en su película como un tributo a los mayas y ha manifestado que él se propuso utilizar la lengua maya yucateca para, no sólo agregar verisimilitud, sino también resaltar el interés en y el respeto por la lengua moderna y sus hablantes. No obstante, para la mayoría de nosotros esta película soñada se convirtió en una pesadilla.

La versión teatral de la película terminó el 8 de marzo de 2007. Durante la presentación de tres meses, esta película se presentó en 2,465 teatros alrededor del mundo. En los Estados Unidos, recogió \$50,866,635; las presentaciones "extranjeras" almacenaron $\$ 67,966,369$; haciendo un total de ganancias mundiales de $\$ 118,833,004$. En cuanto a la crítica, la película fue bien recibida. Aunque las nominaciones ya se habían cerrado para los Oscar del 2007, rápidamente se reabrieron para permitir que Apocalypto se incluyera. La película obtuvo nominaciones por maquillaje, mezcla de sonido y la edición de sonido. La revisión de los votos en-línea (con 631 puntos de referencia) le otorgaron un puntaje a la película, en una escala de A-F, le otorgaron prácticamente sólo As, con $61.6 \%$. Únicamente un $11 \%$ evaluó la película con $\mathrm{F}$ (http://www.boxofficemojo.com/movies/?id=apocalypto. $\mathrm{htm})$.

$\begin{array}{lcr}\text { As: } & 389 & 61.6 \% \\ \text { Bs: } & 116 & 18.4 \% \\ \text { Cs: } & 41 & 6.5 \% \\ \text { Ds: } & 16 & 2.5 \% \\ \text { Fs: } & 69 & 10.9 \%\end{array}$


La película salió al público en DVD el 22 de mayo de 2007, aunque, por supuesto, versiones pirateadas habían salido a luz dentro de pocas horas de las presentaciones, previo a su liberación. La película continúa llegando a miles de espectadores. Llena de imágenes del arte maya, la película es en sí una expresión artística y, así como con otro arte de los mayas, está íntimamente ligada al poder.

Aunque la intención del Señor Gibson era que esta película fuese una alegoría del colapso de Occidente, una denuncia del libertinaje moral de los Estados Unidos, la aparente exactitud de la representación del ambiente maya de Garra Jaguar se presta para las interpretaciones de la película como que fuese "acerca de" los mayas. Como tal, logró una tormenta de reacción tanto de los mayas mismos como de aquellos quienes estudian a los mayas.

El escritor maya yucateco, Jorge Miguel Cocom Pech, en una entrevista para el periódico mexicano La Jornada' manifestó: "Mel Gibson nos debe pedir disculpas, pero los estadounidenses no piden perdón". Él además caracterizó la película como "una porquería". La Jornada citó además al Comisionado Anti-racismo de Guatemala, Ricardo Cajas, diciendo: "(La película) está basada en suposiciones que nos presentan a los mayas como un pueblo bárbaro, asesino, que solamente puede ser salvado por la llegada de los españoles".

Traci Arden, arqueóloga y profesora asistente de la Universidad de Miami, escribió una crítica para la revista Archaeology ${ }^{2}$ en la que ella caracterizó la película como "pornografía". En Washington, D.C. en la reunión de la Asociación Americana de Antropología, la Dra. Arden organizó un panel de investigadores norteamericanos, mexicanos y guatemaltecos, nativos americanos y de descendencia europea para discutir Apocalypto y sus efectos en los mayas vivos. Andrea Stone de la Universidad de Wisconsin-Milwaukee ${ }^{3}$ critica los "acercamientos de guerreros en pillaje quienes parecen ogros babosos, sin cerebro." La comparación con El Señor de los Anillos no es injustificada. Mel Gibson ha defendido de varias formas la violencia que él presenta, entre las cuales (a) no demostrando tanta muerte o destrucción tal como se ve en la trilogía de "Los Anillos" y (b) siendo menos ofensivo para la audiencia moderna de lo que hubiese sido una presentación exacta de las prácticas mayas.

\footnotetext{
${ }^{1} \mathrm{http}: / / w w w . j o r n a d a . u n a m . m x / 2007 / 01 / f 15 /$ index.php?section=espectaculos\&article=a18n1esp

2 http://www.archaeology.org/online/reviews/apocalypto.html

33 de enero de 2007,www.archaeology.org/online/reviews/apocalypto.html
} 
Por supuesto, la evaluación de esta película no vino de los arqueólogos, aunque algunos sí aclamaron públicamente la exactitud de la representación, no sólo con respecto a la decoración y a la vestidura sino también con respecto al sacrificio que se presenta. Hablando sobre el registro arqueológico con respecto a los mayas del pre-contacto, el consultor, Richard Hansen, de la Universidad Estatal de Idaho, dice: "La decapitación está allí, las perchas de cráneos están allí, los cuerpos rodando por las gradas están allí." 4 Hansen repite a Gibson al decir que los mayas eran más sangrientos de lo que se demuestran. También desollaban seres humanos. "El sacerdote llevaba la piel humana, por Dios", dice Hansen. "Se le dio un tono mucho más bajo." Sin dar nombres y mientras salían del teatro, Prensa en México entrevistó a arqueólogos, quienes trabajan para la UNAM. Ellos afirmaron que los mayas en efecto practicaron sacrificio de corazón y bastante parecido a la forma en que se demuestra en la película. Una "víctima" de sacrificio se extendía boca arriba sobre un altar, manteniéndolo en su lugar sujetándolo por los brazos y las piernas; luego el sacerdote sacaba el corazón con una hoja de obsidiana. Estos arqueólogos también ratifican la forma de decapitación que se presenta. Michael D. Coe es famoso por haber hecho broma de que a pesar de las grandes cantidades de gente que sacrificaban los aztecas y los relativamente pocos que los mayas sacrificaban, él preferiría no ser un cautivo maya, debido a su práctica de torturas exquisitas.

En su artículo del Smithsonian sobre "descifrando Tikal", David Roberts anota: "Lejos de ser pacíficos, los mayas eran guerreros, sus reyes déspotas jactanciosos. Las ciudades mayas no eran simplemente ceremoniales; en vez de eso, eran una mezcolanza de feudos inclinados hacia la conquista y hacia una vida en constante miedo de ataque."6 Linda Schele y Mary Miller en The Blood of Kings (1986) atestiguan que: "La sangre era la argamasa de la vida ritual antigua maya."

Louis E. V. Neaver, editor anterior de Mesoamérica, en un comentario para New America Media del 19 de diciembre de 2006, dijo que Apocalypto era emocionante. Él asistió con dos mayas yucatecos, trabajadores de restaurante, a quienes él había

\footnotetext{
4 http://cosmiclog.msnbc.msn.com/archive/2006//12/08/19477.aspx

${ }^{5}$ http://cosmiclog.msnbc.msn.com/archive/2006//12/08/19477.aspx

${ }^{6}$ http://www.smithsonianmagazine.com/issues/2004/july/tikal.php

${ }^{7}$ Fort Worth: Kimbell Art Museum, c1986. The blood of kings: dynasty and ritual in Maya art. Linda Schele, Mary Ellen Miller; fotografías de Justin Kerr.
} 
conocido en Nueva York. Después de la película, dijo que los dos hombres, Pedro Tun y Juan Cantu estaban alegres de escuchar su lengua en la pantalla plateada. Además, él dice, "Era una corriente de adrenalina y pura alegría escuchar aplausos al final de la película, rodeados de blancos, negros y latinos. Saliendo del teatro, Pedro Tun se volvió hacia mi y deseaba saber, "Si esta película tiene éxito, ¿cree usted que de aquí sacarán un juego video? Eso sería nahoch" (así). "Nahoch" (así) quiere decir "una cosa grande" en maya yucateco.

Estuardo Zapeta, un maya, Antropólogo y columnista de periódico en Guatemala, en su columna del Siglo XXI le otorgó una buena crítica a la película, básicamente diciéndole a su cohorte maya que bajara de tono, utilizando la frase "lica", "mano" (¡Es solamente una película!). Arthur Demarest, arqueólogo de la Universidad de Vanderbilt, quien trabaja en la región de Petexbatún en Guatemala, en respuesta le escribió una carta abierta a Zapeta. Quisiera compartir con ustedes una selección de esa carta: "La película me asustó. Es tan racista en todo sentido. Yo estaba preparado para ver babosadas divertidas y no realistas,... mayas cazadores amables y casi infantiles contra los Mayas malvados urbanos sicóticos. Es un concepto de racismo fundamental, no solamente acerca de los mayas, pero en relación a, pero es mucho más que esto. Sepa que no estoy preocupado de ninguna manera sobre los detalles incorrectos ni otros problemas.... Lo que me ofendió fue la imagen general de la comprensión de "culturas" en general. Los líderes indígenas en Guatemala y en todos lados van a gritar hasta el cielo. ¡Y, en este caso, con toda razón!"'. Muchos grupos e individuos mayas protestaron. Maya Visión, grupo con base internacional de trabajadores mayas para ayuda legal, exploraron las posibilidades en cuanto a un litigio legal contra el Señor Gibson. Otros tomaron una posición más similar a la de Zapeta. En una reunión del 3 de enero de la Coordinación y Convergencia Nacional Maya Waqib' Kej, un marcador maya de los días (ajq'ij), expresó de nuevo que era "simplemente" una película. Además, anotó que la representación de los mayas (y/u otros grupos indígenas) como salvajes sedientos de sangre no es nada nuevo; es más bien y simplemente una continuación del proyecto ideológico colonial.

${ }^{8}$ El maya yucateco para "grande" o "grandioso" debería ser nohoch.

${ }^{9}$ Arthur Demarest, carta abierta a Estuardo Zapeta (diciembre 2007): "The picture frightened me. It is racist in every sense of the word. I was prepared to see entertaining, unrealistic foolishness, but it is much more than that. Know that I am not at all worried about the incorrect details and other problems....It is a fundamental concept of racism, not only with regard to the 
Diego Vásquez Monterroso, estudiante de la Universidad del Valle de Guatemala, elabora este tema en su foro: "El poder de la dominación se desplaza entonces a aquellos que tienen el control de los medios de producción cultural, los cuales generalmente comparten la misma ideología que quienes ejercen la dominación por otros medios (coercitivo, intelectual, económico, político, etc.)." ${ }^{10}$

Muchos comentaristas han lamentado la falta de énfasis en la película sobre los logros culturales e intelectuales de los mayas. Cynthia Robin, antropóloga de la Universidad Northwestern, dice sobre los mayas: "Ésta es una de las civilizaciones más avanzadas del mundo en términos de arte, ciencia, astronomía, matemática.... Los mayas son una de las pocas civilizaciones que en realidad inventó el número cero, que permite sistemas complejos matemáticos." ${ }^{11}$ Los científicos y estudiantes del Instituto de Antropología y de Estudios Precolombinos de la Universidad de Bonn en un comunicado de prensa deploraron el potencial nocivo de la película. Allí también alaban los logros no directamente presentados: "Logros culturales de la civilización como, por ejemplo, la evolución de un sistema de escritura totalmente independiente y un sistema de calendario basado en aritméticas (así) que incluía el concepto del "cero", no se mencionan."12 Earl Shorris, escribiendo para The Nation, dice: "La cultura maya antigua fue extraordinaria, tal como lo acepta ahora el resto del mundo. Los mayas inventaron uno de los pocos sistemas fonéticos originales de escritura (nosotros estamos familiarizados con el sistema chino y el que culminó con la escritura latina). Trabajaron con el concepto del cero mucho antes de que el mismo se conociera en Europa. Fueron espléndidos astrónomos. Su arte y su arquitectura se conocen y se estudian hoy día alrededor del mundo."13 Shorris concluye cínicamente: "La cultura no vende boletos. La violencia sí."14

Por supuesto que no sólo se trata de la violencia, se trata también del poder. En parte, el poder para representar historia, hacerla. Los mayas ciertamente entendieron el poder del arte y su habilidad para señalar, apoyar y crear influencia tanto temporal como sagrada.

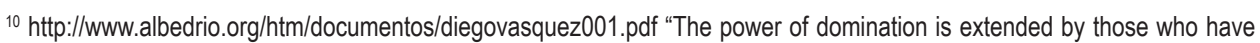
control of the media of cultural production, those who generally share the same ideologies as those who control the media of coercion, intellectual, economic and political power".

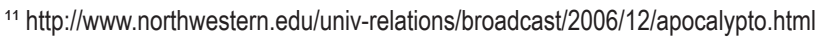

$12 \mathrm{http}: / /$ www.wayeb.org/download/apocalypto/Bonn_english.pdf

${ }^{13} \mathrm{http}: / /$ www.thenation.com/doc/20061218/shorris

${ }^{14}$ op. cit.
} 
El alboroto que le siguió a Apocalypto puede que haya proveído combustible al éxito de la taquilla, bajo la teoría de que "cualquier publicidad es buena publicidad". Los académicos quienes protestaron concedieron entrevistas a periódicos locales y nacionales. Activistas mayas y ONGs han emitido declaraciones. Cartas de protesta circularon en internet y abundan en foros y en otros medios abundantes, pero ninguno de estos medios tiene el poder que tiene la película. Parte del poder de la película descansa en el número de gente a quien llegó la película. Aunque el New York Times tiene una circulación de 1,120,420 no se puede confiar en que toda esta gente lea un artículo específico, ni que lea toda una entrevista con un antropólogo para llegar a la crítica. Además, se cuenta con el poder de la representación visual. La película de Gibson es realmente cinematografía hermosa. Tatuajes, peinados y agujeros se presentan con intenso detalle. Quienes nos hemos imaginado viendo una ciudad maya con su pintura original intacta y hemos tenido que conformarnos con muestras en parques, como la del Parque de Agua Xocomil en Guatemala, podemos suspirar con la vibración de los rojos, amarillos y el azul maya de los edificios de la ciudad en Apocalypto. Los artefactos se han reproducido fielmente. Las páginas de los catálogos de exhibiciones en museos mayas parecen recobrar vida.

Otro aspecto del poder de esta película viene del despliegue de arquetipos. Algunos de estos arquetipos son, si no universales, ampliamente resonantes en la cultura occidental: el cariñoso y devoto papá, la importancia de defender la propia casa y el propio país (ya sea Carolina del Sur en 1776, a la manera del Patriot de Gibson o ya sea a la manera de la "jungla maya" en Apocalypto), políticos corruptos. Otros arquetipos nos llevan a las tradiciones ligadas al colonialismo: mostrando a las poblaciones nativas ya sea como niños, y de tal manera en necesidad del paternalismo, o ya sea como salvajes y de esa manera en necesidad de civilización; como supersticiosos y así con necesidad de los sistemas occidentales de conocimiento o como paganos y así con necesidad de la cristiandad. Las caracterizaciones coloniales y neocoloniales de la gente maya en Guatemala y aun en México, a pesar de la ideología de la raza, demuestran la persistencia de rasgos culturales mayas, prácticas, lenguas y gente como amenazas a la modernización del país, creando divisiones étnicas y reteniendo la difusión del desarrollo económico, tecnológico y nuestra versión de la democracia. Cada uno de estos estereotipos se afirma, se materializa y se dramatiza en Apocalypto.

Probablemente no sea posible escribir un guión para una película de acción-aventura que recrea la invención maya del cero, ni aún las interacciones complicadas de los 
ciclos del calendario maya: la cuenta larga, la cuenta de los 819 días, el ciclo de los 584 días de Venus, la serie lunar, el "año" abstracto de 400 días, el haab' o año solar de 365 días y el tzolk'in o calendario ritual de 260 días. Otros cuentos, teniendo como escenarios el área maya, se han expresado en películas: Tumba Mala: Maldición de los Mayas (2004), con la actuación estelar de Todd Bridges y Joe Estévez; Tarzán y la Diosa Verde (1938), con Herman Brix como el héroe; y Lo que Soñó Sebastián (2003), con Andoni García como el actor principal. Ninguna de estas películas tuvo éxito frente a las otras contemporáneas. El Norte, presentada por primera vez en el Festival del Cine de Telluride en 2003, presenta la lucha de dos mayas guatemaltecos desplazados hacia "el norte" y terminando en Los Ángeles. Se liberó para otros teatros en el 2004 y ganó una nominación al Oscar en el 2005 por considerarse la "mejor comedia original". Esta película volvió los ojos del público espectador de los Estados Unidos hacia la guerra genocida en Guatemala, pero el interés no se mantuvo y la película en sí no fue un éxito. Después de todo, no se categorizó como una película de acción/aventura, más bien apareció en las listas como "Arte/Extranjero y Drama".

¿Pueden la gente indígena, mayas, y los investigadores quienes trabajan con ellos movilizar el poder para compararse al poder del arte de Mel Gibson? El columnista Louis Devereaux censuró una protesta de los cuidadores de los días, ajq'ija' (ajk'in,hmeen) llamándolos "mayas imbéciles." ${ }^{15} \mathrm{Ma}$ Cristóbal Cojti', un ajq'ija' de Tecpán, Guatemala, le contestó a Devereaux en una carta al mismo periódico. Ma Cojti' caracterizó la película como una de "barbarismo originado en Europa y en los Estados Unidos, países que han saqueado a las naciones indígenas soberanas, por medio del genocidio y del etnocidio, negándoles sus cualidades (a estas naciones) como humanas y como sociedades humanas y como culturas civilizadoras." 16

Algo que podemos hacer es educar. Hablar, balancear el arte con el arte. ¿Qué muestra el área maya misma con respecto al sacrificio humano, las imágenes más horribles de Apocalypto, la acusación gráfica del libertinaje de la civilización maya ya para el contacto con los españoles, el meta-texto visual que se iguala con la moral de Will Durant que Gibson utiliza como la marca introductoria para la película: "Una gran civilización no se conquista desde fuera sino hasta que se ha destruido desde dentro"? ${ }^{17}$

\footnotetext{
${ }^{15}$ http://www.opinion.com.gt/Numeros\%20anteriores/190307/asturias.htm

${ }^{16}$ Copia personal antes de su publicación, enviada el 24 de marzo, 2007, Lajuj Imox.
}

${ }^{17} \mathrm{http}: / /$ www.libertyfilmfestival.com/libertas/?p=1218 
Si revisamos las representaciones de la guerra maya, encontramos escenas como aquellas que aparecen en Bonampak, en especial los registros superiores del Cuarto 2, los que demuestran señores mayas en combate entre ellos. A los señores capturados se les lleva prisioneros y se les despoja de toda su indumentaria. Epítetos de los gobernantes de ciudades incluyen títulos como "el de 20 cautivos". Muchas imágenes demuestran a prisioneros solamente con su taparrabos, amarrados, a menudo con sus nombres inscritos sobre su muslo. Los murales de Bonampak también exquisitamente demuestran a cautivos enfrente de los señores victoriosos, esperando o sufriendo ya tortura y sacrificio. Los códices Madrid y Grolier demuestran prisioneros amarrados. El sacrificio de corazón se demuestra explícitamente en las estelas 11 y 14 de Piedras Negras, la cerámica de La Sufricaya, Petén, demuestra corazones atravesados con hojas de obsidiana, en el códice Trocortesiano (79), en el Dresde (3a), en el Templo de los Jaguares y en el de los Guerreros de Chichén Itzá; imágenes en cerámica y en piedra muestran corazones extraídos. También aparecen decapitaciones, las más famosas en el campo de pelota de Chichén, pero también en la vasija de Princeton y en el Códice de Madrid 54b1 y 2. Estos sacrificios ocurrieron, pero en contextos sagrados y no en una línea de espera. Las inscripciones indican que los individuos sacrificados eran nobles, no campesinos cazados como material para el molino de matanza. A los prisioneros se les puede identificar por nombre y por su propia ciudad. El señor Waxaklajuun Ub'aah K'awiil fue capturado por el señor de Quiriguá, quien orgullosamente proclama este hecho en sus monumentos.

El documento Kaqchikel colonial Kiwujil Xajila ${ }^{18}$ confirma que los señores de Iximche' hospedaron a Pedro de Alvarado en una estructura palaciega, en donde fue acechado por visiones de pesadillas que salían del tzompantli (percha de calaveras).

Sin embargo, los mayas no sólo sacrificaban a otros, sino que también ofrecían su propia sangre. Todos estamos familiarizados con el Dintel 24 de Yaxchilán, representando a la Señora K'abal Xook, pasándose una cuerda espinosa por su lengua. Tanto mujeres como hombres comúnmente también se horadaban y se rehoradaban las orejas para sacarse sangre. La sangre se recogía en tela de algodón o en papel, la que luego se quemaba como ofrenda. Los líderes masculinos ofrecían auto-sacrificios perforando sus penes (Dintel 17). Se ha puesto mucho énfasis en

\footnotetext{
${ }^{18}$ Consultar a Judith M. Maxwell y Robert M. Hill, II (2007) Kaqchikell Chronicles, Universitsy of Texas Press, Austin, Texas. La primera sección de la traducción trata de este texto, conocido de varias maneras como "Los Anales de los Kaqchikeles" y "El Memorial de los Señores de Tecpán Sololá".
} 
la naturaleza utilitaria de estos sacrificios. Se sangraba o se hacía ofrendas para invocar a las serpientes de visión, las que abrirían los portales entre los mundos y facilitarían la comunicación con los espíritus ancestrales.

Por medio de los códices sabemos que los mayas también ofrecían pavos y tortillas como sacrificios. Celebraciones particulares demandaban diferentes combinaciones de ofrendas. El sacrificio de gallinas continúa aun hoy día, aunque la mayoría de las ceremonias mayas no involucran la matanza de ningún animal.

Lo que está más sorprendentemente ausente en cuanto a la comprensión del sacrificio antiguo maya, humano, auto, de animal o cualquier otro es el contexto espiritual. Siempre es peligroso remontarse hacia atrás a partir del presente etnográfico, especialmente en un dominio tan ideológicamente cubierto como la religión y la espiritualidad, pero lo que es más ofensivo acerca de la masacre en el templo en Apocalypto no es el hecho del sacrificio, pero más bien su vacío.

En el sacrificio maya moderno, un suplicante provee un toj ${ }^{19}$ ("pago"). Este pago puede ser una simple candela o el esfuerzo que se requiere para llegar a un santuario en la cima de una montaña. Puede ser también una cierta cantidad de bienes rituales, samajib'äl, que solicita el oficiante ajq'ij. La referencia a un altar es como a una "mesa". El ritual y las ofrendas pueden abarcarse bajo el término kotz'i'j que quiere decir "flor". Si el ritual es para agradecimiento o para hacer una petición, puede que se diseñe un altar. Puede que sea el símbolo para Q'anil (Lamat) o el símbolo del día en que el ritual se realiza. El diseño comúnmente se delinea con azúcar, luego se repasa y se rellena con incienso de varios tipos. Candelas de los colores apropiados marcan las seis direcciones cardinales y las esquinas cruzadas. Puede que se añadan hierbas, así como también pan, chocolate, tabaco, alcohol y gaseosa roja. Especialistas en rituales a menudo solicitan una lista de los miembros de la familia del suplicante, vivos y muertos, para solicitar apoyo espiritual para la petición.

El fuego abre un espacio sagrado, un conducto para permitir la comunicación entre los mundos. Las espirales de humo serpenteante y las llamas estallantes proveen al ajq'ij con respuestas visuales desde el mundo espiritual; el cuerpo del celebrante también sirve como un conducto para la comunicación. Este intercambio es sagrado

\footnotetext{
${ }^{19}$ Los términos que utilizó en esta sección son del Kaqchikel. Las prácticas varían entre los mayas que las utilizan, pero la estructura global de los rituales de ofrenda es similar.
} 
y cargado de poder. A los espíritus y a las fuerzas que se invocan se les debe reconocer, se les debe hablar con cuidado, se les debe agradecer y se les debe regresar a su reino. Los especialistas revuelven y vuelven a revolver los tizones para liberar toda la energía. Así como en béisbol, "no se termina hasta que se termina". La práctica en realidad varía. Los Chuj hacen la broma de que los Kaqchikeles y los K'ichee's queman en una ceremonia lo que un Chuj puede ofrecer en un año. No obstante, el elemento más importante, tal como lo anotó un ajq'ij Tz'utujiil, es la actitud de fé y de devoción honesta. Los que participan en las ceremonias, ka'i'kik'u'x ((con) dos corazones) muy a menudo no resisten permanecer en el ritual completo, o se desmayan o se salen del círculo y deambulan a otros quehaceres.

Es el asombro respetuoso frente a lo sagrado lo que hace falta en Apocalypto. El tratamiento académico que se les ha dado a los sacrificios mayas de prisioneros ha enfatizado el asombro y el miedo de los gobernantes, presumiblemente una actitud que promovían los mismos gobernantes e.g. Karl Taube (2002) ${ }^{20}$. Pero las escenas de sacrificio grabadas y pintadas no están desprovistas de lo sagrado. Mientras que nuestra visión de los gobernantes antiguos mayas ya no acepta más a los teólogos/líderes pacíficos, aceptamos que lo sagrado y lo mítico forman una gran parte de la producción iconográfica y escrita del período Clásico. Los libros mayas o códices que nos quedan están dedicados al calendario, a la predicción y a la adivinación. No debemos olvidar que la raíz de adivinación es "divino".

Concluyo con el mismo dilema con el que comencé. Los niños mayas que ven la acción espectacular de Mel Gibson salen más inclinados a creer en el mantra que se repite en sus libros de texto: que sus ancestros eran salvajes quienes se hicieron "civilizados" o "gente decente" gracias a los esfuerzos de los "conquistadores" y de sus sacerdotes. La práctica del sacrificio, tal como se presenta en la película, no contiene nada de lo sagrado y mucho de lo cruel y de lo sádico. La presentación artística de Gibson de la vida y de los tiempos mayas resuena con paneles selectos de auténtica escritura y arte mayas para fundir de nuevo a los mayas en la imagen de los villanos arquetipos. Quizá la visión de J. E. Thompson sobre los pacíficos astrónomos teócratas sea extralimitada, pero Apocalypto, trabajo artístico único del siglo XXI, parece tener el poder de borrar el arte maya de los últimos 13 b'aktunes. ¿Cómo podemos nosotros como investigadores explicar las prácticas verdaderas

\footnotetext{
${ }^{20} \mathrm{El}$ arte olmeca en Dumbarton Oaks. http://www.doaks.org/OlmecArt.pdf
} 
de los mayas de manera que no los condenemos por la moral de otro tiempo y de otro lugar, mientras que al mismo tiempo mantengamos la atención de posibles interesados en lo maya, quienes podrían agregarse a la lista de aquellos quienes pueden ayudar a los mayas contemporáneos en su lucha por justicia social, salarios que permitan vivir, educación autóctona, libertad religiosa y desarrollo artístico?

¿Cómo podemos contextualizar apropiadamente la violencia real entre los valores culturales igualmente reales de los mayas, especialmente aquellos apreciados por los mayas vivientes: respeto (respeto por la tierra, por objetos que los occidentales ven como inanimados, por todos los seres animados); amor familiar; y responsabilidad familiar/comunal? Mel Gibson ha demostrado el poder que el arte todavía tiene sobre los mayas, aunque en este caso el poder se ejerce desde fuera. Mel Gibson ha llegado a millones de gente con esta visión. El 22 de mayo del 2007, copias legales comenzaron a circular en DVD. ¿Cómo pueden competir nuestras teorías sobre los modos de vida de los mayas, cuidadosamente moduladas y contextualizadas, en cuanto al pre-contacto (y post-contacto)?

\section{Posdata}

Durante la discusión de mesa redonda que le siguió a esta presentación, el Dr. Richard Hansen solicitó modular la crítica de la película. Él enfatizó tres puntos: (a) él y el Sr. Gibson rechazan la visión de los mayas presentada como "racista"; (b) se pudo haber presentado escenas mucho más sanguíneas que hubieran horrorizado y repelido más al público espectador, obteniendo así un mayor clamor y una acusación más fuerte de los mayas, tanto de los "antiguos" como de sus descendientes modernos; (c) el Sr. Gibson ha ayudado a muchos mayas con sus donaciones filantrópicas; (d) no fue la intención de que la llegada de los españoles presagiara la destrucción de la gran, pero corrupta civilización maya, tal como se le presentó en la cita de Durant, pero se le incluyó fuera de contexto cronológico debido al hecho que la ciudad que aparece era básicamente un centro urbano del Período Clásico, para presagiar una posible secuencia, a ser producida por el Sr. Gibson, siempre con la asistencia y parecer técnicos del Dr. Hansen. Permítaseme cada punto a la vez brevemente.

1. No fue la intención que esta película fuera racista. El héroe y sus pacíficos vecinos aldeanos son mayas, según la concepción de la película. No obstante, su estilo de vida selvático y de pre-agricultura había desaparecido en las tierras 
bajas mayas varios siglos antes del período Clásico. Los habitantes urbanos y sus guerreros pillos también son mayas. De manera que tanto el mal como el bien se presentan como étnicamente mayas. Pero el concepto popular de "maya" se liga a la gente y cultura de se liga a los imponentes templos, palacios, plazas con estelas y altares, esculturas y frescos. Son estos los mayas que se toman como las madres y los padres fundadores de las ciudades, tanto antiguas como modernas, de Mesoamérica, los ancestros de las 32 comunidades lingüísticas actuales quienes hablan lenguas descendientes del Proto-Maya y quienes continúan practicando estilos de vida milenarios. Por supuesto, no es solamente este grupo que sufre la caracterización de la alta cultura del sur y este de México, Guatemala, Belice y norte de Honduras y de El Salvador como sadistas corruptos; la materialización del estereotipo del "Indio" como salvaje daña a todos los grupos indígenas. Esta difamación dañina es particularmente peligrosa porque los grupos primarios de las Américas continúan marginados en sus países de origen. Cuando yo le pasé la película a la clase sobre la Lengua y la Cultura Kaqchikel, Oxlajuj Aj, una de las maestras, mujer de Santa María de Jesús, salió llorando después de estar viendo solamente la primera media hora. La brutalidad trajo a su mente el entrenamiento y la inducción forzada de los mayas a la famosa tropa genocida, irónicamente llamada Kayb'il B'alam. Los pozos de cuerpos no enterrados le trajo a la mente las fosas comunes de las víctimas de la "Violencia" reciente, experimentada entre los mayas guatemaltecos. Ella se identificó con las víctimas y con los perpetradores, todos mayas, todos estropeados horriblemente por fuerzas políticas y agendas externas. Esta película invita a los espectadores, maya y no maya, a identificar a los mayas con la brutalidad, la matanza salvaje, la explotación cínica de formas religiosas, el elitismo, la devastación ecológica, todos aspectos horrorosos para los practicantes de la cultura maya moderna. Considerando que invita a un estereotipo negativo de un grupo de gente, étnicamente identificado, a esta película se le puede considerar racista.

2. Se pudo haber mostrado escenas mucho más sangrientas y escenas mucho más fieles en cuanto al sacrificio maya. A partir de murales, como los de Bonampak, sabemos que los mayas en realidad torturaban a algunas de sus víctimas. Las caras de los cautivos de la pared norte del Cuarto 2 revelan el temor con el que esperan su presentación ante el señor conquistador. Sangre chorrea de los dedos de algunos individuos sentados en la segunda grada. Mary Miller ha sugerido (comunicación personal) que sus uñas se les han sacado. Sabemos, también, que se les sacaban los ojos. Varios dibujos de los códices muestran a 
deidades con ojos extra. Tanto en los códices como en la cerámica, aparecen calaveras con un ojo colgando del alargado nervio óptico. También sabemos que la práctica azteca de desollar una víctima, conservando su piel y luego ponérsela para realizar bailes en honor a Xipetoltec se practicaba en mucha del área maya. Calendarios coloniales de las Tierras Altas mayas registran un mes de Xipetlacalhuiliztli, el período de veinte días durante el cual se celebraba el festival de la deidad desollada. Siempre es espantoso representar la tortura en película. Tanto sensibiliza como desensibiliza a la audiencia. Presentar más detalle en cuanto al sufrimiento de los cautivos antes del sacrificio ciertamente hubiera creado una atmósfera de aun más disgusto. Sin embargo, debe señalarse que el sacrificio que se demostró fue fiel en cuanto al métodouna víctima/ofrenda se extiende sobre el altar, luego se le sacó el corazón, todavía palpitando-pero no fue fiel en cuanto a la cantidad de víctimas. Las decapitaciones, según el registro epigráfico, parece que ocurría en otros contextos. No existe evidencia de que los cuerpos fuesen descuartizados y distribuidos, según las versiones coloniales de la práctica azteca en templos. Las fosas comunes, recordando a Auschwitz o a Tres Pilas, evocan reacciones viscerales, pero no aparecen en los registros arqueológicos. El conteo de los cuerpos que se refleja en la película tiene efecto cinematográfico, pero refleja la matanza de los mayas por las tropas del gobierno guatemalteco en los 1970 s y 80 s, y no la práctica de maya contra maya, ya sea en el Clásico o en el Postclásico.

3. El Sr. Gibson ha ayudado a muchos mayas con sus donaciones filantrópicas. El Dr. Hansen enfatizó las grandes donaciones que el Sr. Gibson ha hecho a diferentes grupos quienes trabajan con poblaciones mayas. Esta filantropía es, por supuesto, de notarse y de apreciarse. Pero, por su naturaleza, es específica y por partes y no compensa el gran impacto negativo en los mecanismos estatales de apoyo y de desarrollo causados por la ratificación de los prejuicios de los legisladores. El Presidente de Honduras, José Manuel Zelaya Rosales, en la recepción final de la conferencia en Copán, me comentó que la película de Gibson estaba en error, no en cuanto a la caracterización de los mayas o de la gente indígena, sino en hacer de la historia una historia personal, en vez de una acusación genérica. Opinaba que esa visión brutal y sangrienta de la gente indígena es verídica y justifica políticas contemporáneas de asimilación apresurada y la relegación de la cultura maya al patrimonio nacional, pero histórico, fosilizado, no actual, vibrante, y relevante. Sin embargo, el interés del Sr. Gibson en los mayas no parece ser simplemente utilitario. La película 
ya pasó, pero el Sr. Gibson continúa buscando maneras para influenciar positivamente el cambio para los mayas. La semana del 13 al 17 de agosto de 2007 la pasó en Guatemala, platicando con el Presidente Berger y con miembros del Congreso. En el Congreso de Estudios Mayas, del 8 al 10 de agosto del 2007, en la Universidad Rafael Landívar, los representantes mayas, sin embargo, vieron la necesidad de que el Sr. Gibson reparara el daño a la imagen pública de los mayas en el campo en el que él es maestro, la filmografía.

4. La llegada de los españoles al final de la película no presagia 500 años de exterminación y de evangelización, sino que más bien presagia otra película venidera para demostrar las experiencias de los sobrevivientes de un naufragio y la asimilación y la resistencia subsiguientes de un español. Los espectadores, sin embargo, no están enterados de esta intención direccional. Además, se nos ha avisado con tiempo, en la cita inicial de Duran, que una "gran civilización" será destruida desde fuera (por los españoles), después de haberse destruido desde dentro. Además, disponemos de los pasados 500 años de historia para darnos a conocer la suerte de los mayas y de otros grupos indígenas. Los estimados en cuanto a la reducción de la población varían desde un $80 \%$ en el área maya hasta un $90 \%$ en el norte de México y en el este de los Estados Unidos y un $100 \%$ en los casos de algunos grupos sin nombre de los llanos centrales cimeros, a quienes conocemos únicamente por sus casas y sus esqueletos con viruela. La política colonial española era explícitamente "espada y cruz". Una vez que se determinó que las poblaciones indígenas de América tenían alma, a los sacerdotes se les ordenó salvarlos, aun a costa de los cuerpos que los albergaban. Un líder Taino se rehusó a ser bautizado, antes de su ejecución, por continuar sus prácticas religiosas, diciendo que él no quería ir a un cielo que albergaría a los crueles españoles (Cristóbal Cojti', Congreso de Estudios Mayas 2007). La Inquisición trabajó asiduamente en el Nuevo Mundo para erradicar prácticas antiguas. El Arzobispo Diego de Landa es famoso por el número de libros mayas divinatorios que él quemó, pero clérigos subsiguientes continuaron el trabajo de reunir y destruir los textos sagrados. Ajq'ija', hmeen, ajk'in, ajpatan, ajsamaj, ajk'uh, son guías mayas espirituales, que todavía continúan caracterizándose como brujos. Muchos todavía continúan ofreciendo servicio a sus clientes, pero únicamente sin que los miren sus vecinos. Fieles evangélicos continúan destruyendo sitios sagrados; la Iglesia Católica continúa identificando centros rituales y redefiniéndolos como espacios católicos, erigiendo allí capillas y cruces. La retórica de la diversidad está comenzando a aparecer en cursos universitarios y en algunos documentos políticos, como en la Constitución guatemalteca de 1985, en la convención ILO 169 y en la 
Declaración de la ONU sobre los Pueblos Indígenas. Pero esta retórica está luchando para hacer la transición hacia la acción. México y Guatemala tienen entes gubernamentales que están encargados de eliminar la discriminación, el racismo y la persecución religiosa. La necesidad de esta protección viene del choque cultural que comenzó, así como termina esta película, con la invasión española. 